Психология. Журнал Высшей школы экономики.

2011. T. 8, № 1. С. $78-88$.

\title{
ВЛИЯНИЕ ПРОЦЕССОВ ВНИМАНИЯ НА ПРОГРАММИРОВАНИЕ САККАДИЧЕСКИХ ДВИЖЕНИЙ ГЛАЗ У ЧЕЛОВЕКА
}

\author{
М.В. СЛАВУЦКАЯ, В.В. МОИСЕЕВА, В.В. ШУЛЬГОВСКИЙ
}

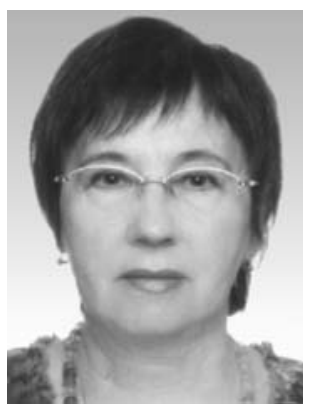

Славуцкая Мария Валерьевна - ведущий научный сотрудник биологического факультета МГУ им. М.В. Ломоносова, доктор биологических наук. Автор 45 научных статей в ведущих российских и зарубежных журналах, посвященных проблеме корковых механизмов внимания и программирования саккады у человека. Контакты: mvslav@yandex.ru

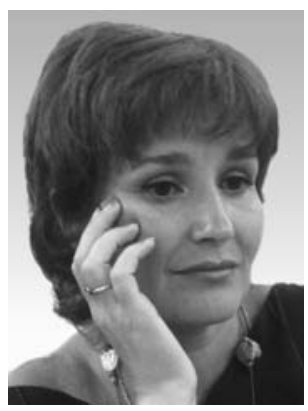

Моисеева Виктория Владимировна - старший научный сотрудник биологического факультета МГУ им. М.В. Ломоносова, кандидат биологических наук. Автор 23 научных статей, посвященных проблеме межполушарной асимметрии процессов внимания и программирования саккады.

Контакты: vikmoi@mail.ru

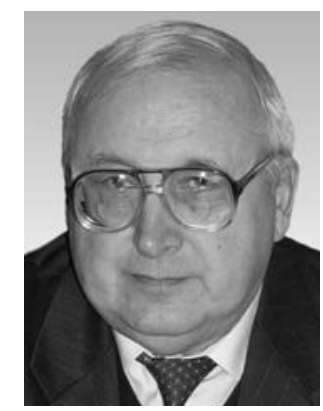

Шульговский Валерий Викторович - заведующий кафедрой биологического факультета МГУ им. М.В. Ломоносова, доктор биологических наук, профессор. Автор 100 статей, 3 монографий и 5 учебников, посвященных различным аспектам высшей нервной деятельности человека и животных.

Контакты: shulg@mail.ru 


\section{Резюме}

Приведены данные об отражении механизмов внимания и программирования саккады в выраженности и топографии усредненных потенциалов ЭЭГ, связанных с подготовкой саккады у человека. Использование психофизиологических схем зрительной стимуляции («Step», «Gap», «Overlap», «Cost-benefit» $u$ «антисаккадическая») показало вклад различньх видов внимания в подготовку и программирование саккады. Установлено, что участие прочессов внимания в контроле саккадческих движений глаз осуществляется с помощью фронто-париетальных сетей коры и фронто-медио-таламической и таламо-париетальной модулирующих систем избирательного внимания.

Ключевые слова: внимание, программирование, саккадические движения глаз, латентный период, пресаккадические потенииаль ЭЭГ.

Проблема внимания является одной из центральных в психологии и психофизиологии. Перспективным в этой области является изучение корковых механизмов программирования саккадических движений глаз, которые являются неотъемлемым компонентом зрительного восприятия и включены во все виды деятельности человека. Клинические и нейрофизиологические данные свидетельствуют о тесной взаимосвязи внимания и движения глаз, а также о функциональном и анатомическом перекрытии структур, контролирующих эти процессы, на всех уровнях головного мозга (Подвигин и др., 1986; Fischer, Breitmeyer, 1987; Becker, 1989; Coull, 1998).

Механизмы программирования саккадических движений глаз находят отражение в топографии связанных с их подготовкой усредненных потенциалов ЭЭГ головного мозга человека (Славуцкая и др., 2008; Jagla et al., 1994; Everling et al., 1997 и др.). Однако существуют лишь единичные исследования, посвященные изучению потенциалов ЭЭГ в латентном периоде саккады.
Цель работы - изучение влияния внимания на программирование саккады в различных условиях зрительной стимуляции, что находит отражение в величине латентного периода саккады и параметрах и топографии усредненных потенциалов ЭЭГ.

\section{Материалы и методы исследования}

\section{Испьтуемые}

В экспериментах участвовали 57 здоровых праворуких испытуемых с нормальным зрением в возрасте 20-25 лет, мужчины и женщины, студенты и сотрудники Московского государственного университета. Все испытуемые дали письменное согласие на участие в эксперименте.

\section{Оборудование}

Электроэнцефалограмму (ЭЭГ) регистрировали с помощью энцефалографа (EEG 16S «MEDICOR) монополярно по международной схеме 10-20 с верхней границей фильтров 
70 Гц. В различных сериях экспериментов регистрировали от 5 до 14 отведений ЭЭГ с поверхности головы по международной схеме $10-20 \%$ с постоянной времени $0.3,1$ или 1.5 с в зависимости от серии эксперимента. Референтом служил объединенный ушной электрод. Горизонтальные движения глаз регистрировали биполярно с помощью электроокулограммы (ЭОГ) с постоянной времени $0.3 \mathrm{c}$.

Управление экспериментом, сбор и хранение данных проводили с помощью персонального компьютера IBM PC AT 486. Скважность считывания сигналов составляла 5 мс. Для предъявления зрительной информации определенного паттерна, анализа латентного периода (ЛП) саккады, параметров ЭЭГ и ЭОГ использовали интегрированную систему

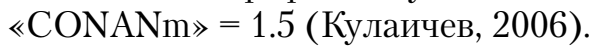

\section{Стимуль и прощедура эксперимента}

Для зрительной стимуляции применяли красные светодиоды $(d=10$ угл. мин), прикрепленные к горизонтальной и вертикальной осям полусферы, подвешенной на расстоянии 60 см от глаз испытуемого. Один из светодиодов служил в качестве центрального фиксационного стимула (ЦФС). Периферические целевые зрительные стимулы (ПЗС) располагались на расстоянии 5,10 и 20 угл. град. справа и слева от ЦФС по горизонтальной оси.

Для усиления внимания испытуемого к экспериментальным условиям использовали методику самоинициации: испытуемый произвольно нажимал кнопку правой рукой и удерживал ее во время реализации стимулов. При уменьшении яркости ПЗС в два раза («пригасание») ис- пытуемый, согласно инструкции, должен был как можно быстрее отпустить кнопку.

Исследование включало четыре серии экспериментов, в которых были использованы стандартные экспериментальные схемы, разработанные в психофизиологии для исследования стадий программирования саккады и их взаимосвязи с процессами внимания (рисунок 1):

Схема 1. Последовательное предъявление ЦФС и ПЗС (Step-схема; Saslow, 1967).

Схема 2. Предъявление ЦФС и ПЗС с межстимульной паузой в 200 мс (Gap-схема; там же).

Схема 3. Предъявление ЦФС и ПЗС с «перекрытием» в 200 мс (Overlap-схема; там же).

При использовании схем 1-3 испытуемый должен был фиксировать взор на ЦФС и при включении целевого стимула (ПЗС) как можно быстрее перевести на него взор, а при «пригасании» ПЗС как можно быстрее отпустить нажатую в начале реализации кнопку и перевести взор на центральный стимул. В серии 1 в одном и том же эксперименте равновероятностно предъявляли зрительные стимулы по схемам 1 и 2 , а в серии 2 - по схемам 1 и 3 . Применялась как бинокулярная, так и монокулярная зрительная стимуляция в правый и левый глаз.

Схема 4 (серия 3) - вероятностное предъявление стимулов, направляющих внимание в одно из зрительных полуполей (Cost-benefit-схема; Posner, 1980). В этой схеме использовали дополнительные стимулы: СС сигнальные стимулы, расположенные в 5 угл. град. слева и справа от ЦФС, и УС - установочные стимулы, 
Экспериментальные схемы, используемые в эксперименте.

Серые прямоугольники обозначают «пригасание» ПЗС

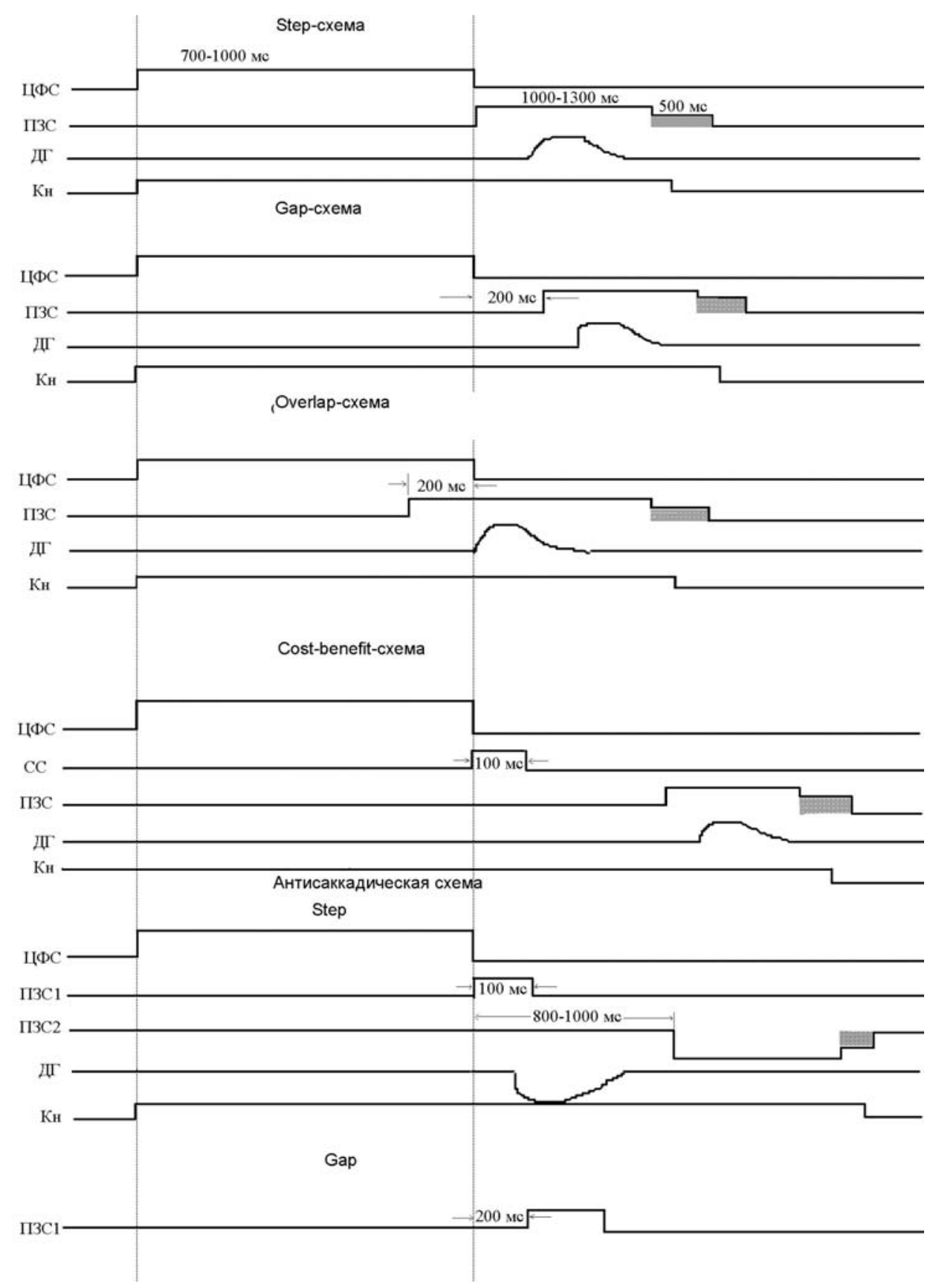


расположенные на вертикальной оси на расстоянии 5 угл. град. сверху и снизу от ЦФС. Верхний УС сигнализировал о высокой вероятности (80\%) совпадения сигнального и целевого стимулов в одном и том же зрительном полуполе. Нижний УС сигнализировал о равновероятностном совпадении и несовпадении СС и ПЗС (50\%). Интервал между выключением СС и включением ПЗС варьировал от 1000 до 1200 мс

Схема 5 (серия 4) - произвольные саккады в симметричную к ПЗС точку зрительного полуполя (Антисаккадическая схема; Hallett, Adams, 1980). Испытуемому давали инструкцию фиксировать взор на центральном стимуле и при включении периферического стимула (ПЗС1) как можно быстрее совершить движение глаз в симметричную точку зрительного полуполя (антисаккада). Через 800-1000 мс после выключения ПЗС в этой точке пространства включался светодиод (ПЗС2), при пригасании которого необходимо было как можно быстрее отпустить нажатую в начале реализации кнопку. ЦФС и ПЗС1 предъявляли как последовательно, так и с межстимульным интервалом в 200 мс.

Во всех схемах экспериментов длительность ЦФС варьировала от 800 до 1000 мс, а ПЗС - от 1000 до 1200 мс. Длительность СС, УС (схема 4) и ПЗС1 (схема 5) равнялась 100 мс. Во всех сериях эксперимента испытуемым предъявляли от 300 до 1200 стимулов в течение $1-4$ опытов.

\section{Анализ данных}

С помощью программного обеспечения «CONANm» для каждого испытуемого вычисляли средние значения ЛП саккады $(M)$, значение главной моды ( $M^{\prime}-$ при отличии гистограммы распределения значений ЛП от нормального), стандартное отклонение $(\sigma)$ и ошибку среднего (m). В сериях 1 и 2 саккады подразделяли на 3 группы: среднелатентные (ЛП = M' \pm 20 мс), коротколатентные (ЛП $<\mathrm{M}-\sigma)$ и длиннолатентые (ЛП > $>+\sigma)$ саккады. В сериях 3 и 4 исследовали пресаккадические потенциалы только в группе саккад со средней величиной латентного периода.

Для детального анализа топографии фокусов ЭЭГ-потенциалов использовали метод компьютерной графики типа «картирования» амплитуды с шагом 10 мс. Стандартную статистическую обработку данных осуществляли с помощью статистических пакетов STADIA 6.1 и MS Excel. Достоверность различий средних значений изучаемых показателей вычисляли с помощью непараметрического парного критерия Вилкоксона.

\section{Результаты исследования и их обсуждение}

Было показано уменьшение ЛП саккады на 30-50 мс при введении межстимульной паузы между фиксационным и целевым стимулами (Gap-схема) и появление группы экспресс-саккад с ЛП 90-120 мс $(p<0.001$, «gар-эффект», рисунок 2$)$. При предъявлении ЦФС и ПЗС с «перекрытием» наблюдалось увеличение ЛП саккады на 40-70 мс и появление группы длиннолатентных саккад ( $p<0.001$, «overlap-эффект»). Эти эффекты были неоднократно 
Рисунок 2

Гистограмма величины ЛП саккады при последовательном предъявлении стимулов (Step-a) и с межстимульным интервалом (Gap). По оси абсцисс - величина ЛП саккады в мс, по оси ординат - число саккад на целевой стимул
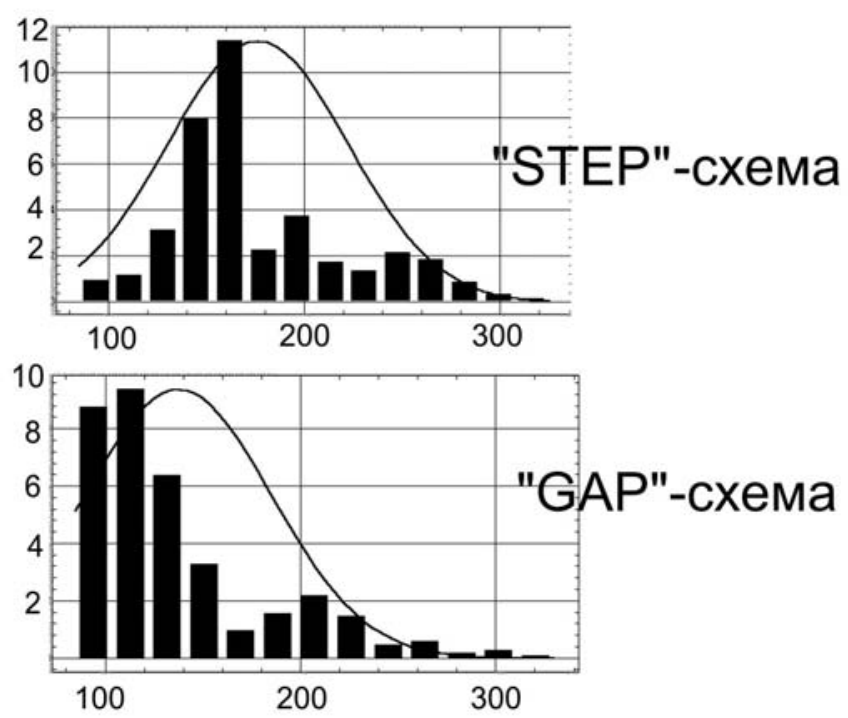

описаны ранее (Fischer, Breitmeyer, 1987; Saslow, 1967). Сопоставление полученных нами данных в условиях изменения процессов фиксации и внимания подтвердило представления об участии процессов «сброса» внимания и освобождения саккадической системы от фиксации в программировании саккадических движений глаз (Fischer, Breitmeyer, 1987; Pratt, 1998; Reuter-Lorens et al., 1984).

Анализ усредненных кривых биопотенциалов мозга в интервале 150-250 мс перед началом саккады при усреднении от начала саккады выявил у всех испытуемых комплекс быстрых негативных и позитивных волн длительностью от 40 до 120 мс и амплитудой от 0.8 до 5 мкВ $(\mathrm{N}-1$, P-1, N-2, P-2) (рисунок 3).

Была установлена зависимость этих потенциалов от способа усред- нения ЭЭГ, от соотношения временных параметров фиксационного и целевого стимулов, от направления саккады, величины ее латентного периода, стимуляции ведущего или неведущего глаза, сложности задачи и влияния направленного внимания.

Сопоставление выраженности и топографии пресаккадических потенциалов в интервале латентного периода саккады в различных сериях эксперимента позволило разделить их на две функциональные группы: «ранние» потенциалы: Р-2 и N-2, с латентностью пика 200 и 150 мс соответственно от начала саккады, и «поздние» потенциалы: Р-1 и N-1, с латентностью пиков 100 и 50 мс соответственно. «Ранние» потенциалы представлены в первой половине интервала латентного периода саккады, a «поздние» - во второй. 
Рисунок 3

Усредненные кривые биопотенциалов ЭЭГ перед саккадами в схеме Step (a) и Gap (б). Пунктирная линия обозначает начало саккады, сплошные линии - моменты выключения ЦФС и включения ПЗС

a

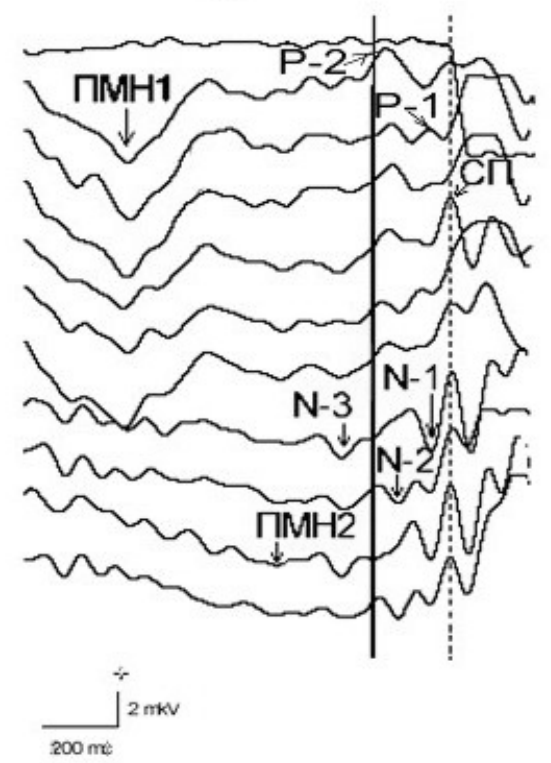

Сравнение параметров и топографии потенциалов Р-2 и $\mathrm{N}-2$ при обратном усреднении от начала саккады и при прямом усреднении от включения стимула в различных экспериментальных условиях дало основание предполагать, что «ранние» потенциалы отражают процессы перцептивного внимания, связанного с восприятием целевого стимула, а также пространственного внимания, включающего в себя процессы двигательного прогнозирования. Включение процессов внимания и неспецифической активации коры в генерацию саккады подтверждается усилением активации сагиттальных областей лобной и теменной коры $(\mathrm{Fz}, \mathrm{FCz}, \mathrm{Cz}$ и $\mathrm{Pz})$ при развитии «ранних» потенциалов. Согласно нейро-
6

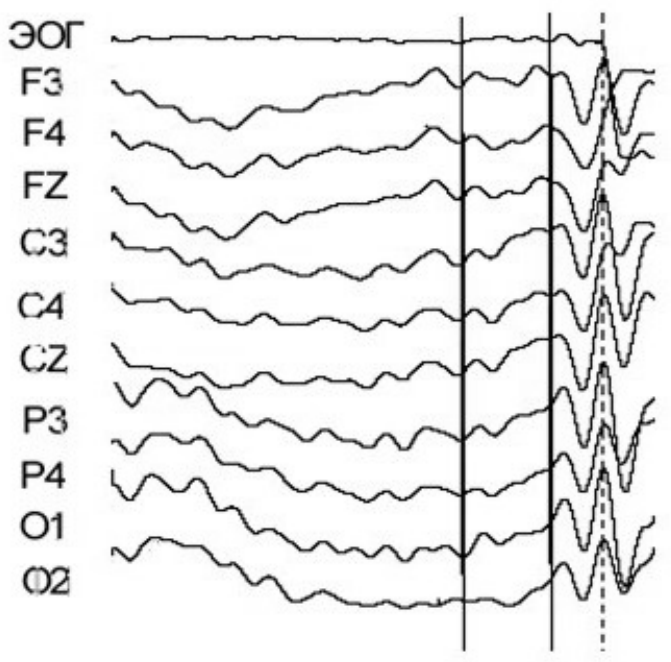

физиологическим данным, в эти зоны коры проецируются фронто-медиоталамическая и теменно-париетальная модулирующие системы избирательного внимания (Мачинская, 2003; Laberge, 2000).

Фокусы «поздних» потенциалов преобладали в основных глазодвигательных полях лобной и теменной коры, контрлатеральных к направлению саккады, что дает основание предполагать, что они отражают командные процессы инициации саккады. Близкие по параметрам потенциалы были выделены ранее перед движением руки (Shibasaki et al., 1980). При развитии потенциала Р-1 его фокусы распространялись также на ипсилатеральное полушарие, что может быть связано с вовлечением 
процессов активного торможения ипсилатеральных глазодвигательных структур коры как необходимого компонента процессов инициации.

Пространственно-временная динамика «поздних» потенциалов в серии 1 (схемы 1 и 2) позволила предположить, что появление экспресс-саккад при предъявлении ЦФС и ПЗС с межстимульной паузой может быть связано с усилением пространственного и моторного внимания в виде опережающих процессов двигательной преднастройки, включающих активацию инициирующих корковых структур. Возможно, что в фоне перед экспресс-саккадами существует повышенный уровень готовности к ее выполнению и процесс «сброса» внимания может начинаться еще до выключения центрального стимула.

В условиях направленного внимания (серия 3, схема 4) было показано усиление и ускорение процессов инициации саккады, что проявлялось в уменьшении латентности пиков «поздних» потенциалов на 10-20 мс и в увеличении их амплитуды на 1-2 мкВ $(p<0.05)$. Топография этих потенциалов позволяет предположить, что в условиях скрытой ориентации внимания в период инициации саккады происходит активация ведущих глазодвигательных зон фронтальной и префронтальной коры (Gaymard et al, 1998), фронто-париетальных сетей пространственного внимания, а также фронто-медио-таламической модулирующей системы (Мачинская, 2003; Posner, 1980; Coull, 1998; Laberge, 2000).

Состояние ожидания и готовности в период фиксации глаз в различных экспериментальных услови- ях нашло отражение в параметрах медленных негативных потенциалов фронто-центральной и теменно-затылочной локализации (ПМН1 и ПМН2, рисунок 4), аналогов раннего и позднего компонентов волны CNV, которую рассматривают как коррелят процессов активации, внимания, мотивации и прогнозирования в период двигательной преднастройки (Кануников, 1980; Shibasaki et al., 1980).

Перед антисаккадами (схема 5), организация которых требует усиления процессов внимания, произвольного контроля и принятия решения, наблюдалось увеличение амплитуды медленной пресаккадической негативности и преобладание ее фокусов в правом полушарии (рисунок 4). Клинические данные демонстрируют доминирование правого полушария в процессах активации и внимания (Брагина, Доброхотова, 1988; Posner, 1980).

В условиях направленного внимания (схема 4) в интервале между сигнальным и целевым стимулами наблюдался неоднократный переход фокусов волны ПМН из лобных зон коры в теменно-затылочные и височные и обратно, включая и лобнои центро-сагиттальные зоны (рисунок 5). Можно предположить, что в условиях фиксации глаз в центре зрительного поля в отсутствие центрального стимула подобная динамика волны премоторной негативности является коррелятом поддерживающего внимания (Coull, 1998; Laberge, 2000), природа которого тесно связана с хранением пространственной информации о локализации зрительной цели в рабочей памяти («моторный образ» или «след внимания» - 
Рисунок 4

Фрагменты картирования амплитуды потенциала ПМН1 в интервале 875-675 мс (а), и потенциала ПМН2 в интервале 685-485 мс (б), до начала саккады влево у испытуемого

П.P. в Step-схеме. Число усреднений $n=41$ (а), 35 (б), шаг картирования 10 мс.

a

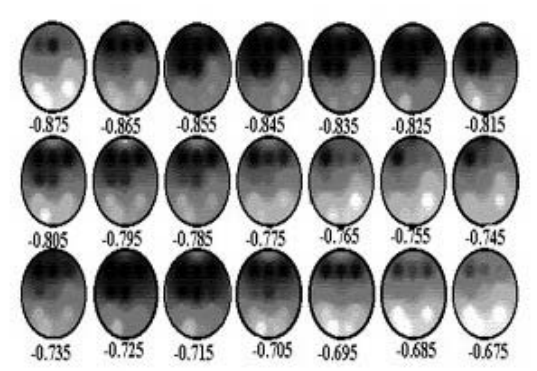

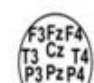

б
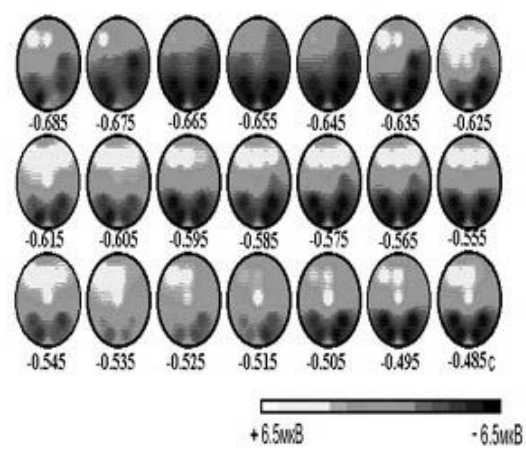

Рисунок 5

Фрагменты картирования амплитуды потенциала PMN перед саккадой влево в экспериментальной схеме «cost-benefit» у испытуемой T.E. за 610-410 мс до начала саккады в условиях направленного внимания (а) и в нейтральных условиях (б). Фокусы темного

цвета соответствуют медленной негативной волне. Число усреднений $n=40$, шаг картирования 10 мс

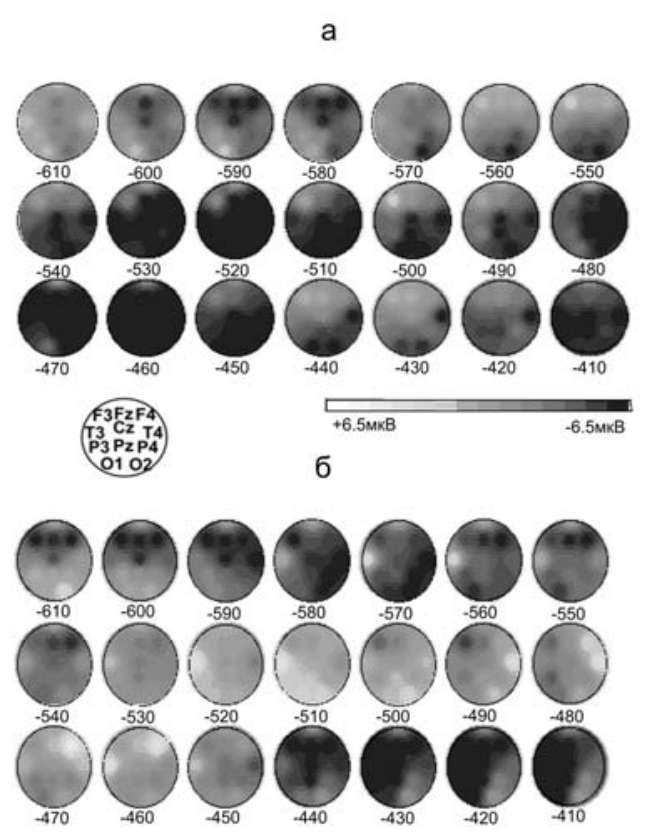


Jeannerod, 1994; Наатанен, 1998), и отражает циркуляцию нервных импульсов по фронто-париетальным сетям коры.

\section{Заключение}

Таким образом, проведенное исследование показало включение процессов внимания в подготовку саккады не только в интервале латентного периода, но также и во время фиксации глаз, что отражает формирование установки в соответствии с требованиями инструкции, сопровождающейся активацией ведущих глазодвигательных зон коры. Полученные нами данные позволяют рассматривать внимание как совокупность разнородных процессов (Coull,
1998). В условиях нашего эксперимента можно выделить такие виды внимания: перцептивное (селективное), усиливающее восприятие целевых зрительных стимулов, поддерживающее (установочное) при длительном действии стимула или его ожидании, связанное с процессами памяти и моторное («attention to action»), облегчающее премоторные процессы на всех этапах подготовки саккады. Полученные данные показали, что участие процессов пространственного внимания в контроле саккадических движений глаз осуществляется с помощью фронтопариетальных сетей коры, включающих также фронто-медио-таламическую и таламо-париетальную модулирующие системы.

\section{Литература}

Брагина Н.Н., Доброхотова Т.А. Функциональные асимметрии человека. М.: Медицина, 1988.

Кануников И.Е. Условная негативная волна (CNV) как электрофизиологический показатель психической деятельности // Физиология человека. 1980. Т. 6. № 3. C. 505-519.

Кулаичев А.П. Методы и средства комплексного анализа ЭЭГ данных. М.: ФОРУМ-ИНФРА, 2006.

Мачинская Р.И. Нейрофизиологические механизмы произвольного внимания (аналитический обзор) // Журн. высш. нерв. деят. 2003. Т. 53, № 2. С. 133-150.

Наатанен Р. Внимание и функции мозга. М.: Изд-во Моск. ун-та, 1998.

Подвигин Н.Ф., Макаров Ф.Н., Телепин Ю.Е. Элементы структурно-функ- циональной организации зрительно-глазодвигательной системы. Л.: Наука, 1986.

Славуиккая М.В., Моисеева В.В., Шульговский В.В. Внимание и движения глаз. Психофизиологические представления, нейрофизиологические модели и ЭЭГ-корреляты // Журн. высш. нервн. деят. 2008. T. 58, № 2. C. 133-152.

Becker W. Saccadic eye movements as a control system // R.H. Wurtz, M.E. Goldberg (eds.).The neurobiology of saccadic eye movements. Elsevier Science Publisher BV (Biomedical Division), 1989. P. 13-67.

Coull J.T. Neural correlates of attention and arousal insights from electrophysiology, functional neuroimaging and psychopharmacology // Progress in Neurobiology. 1998. 55. 343-361. 
Everling S., Korappmann P., Flohr H. Cortical potentials preceding pro- and antisaccades in man // EEG Clin. Neurophysiol. 1997. 102. 356-362.

Fischer B., Breitmeyer E. Mechanisms of visual attention revealed by saccadic eye movements // Neuropsychologia. 1987. 25. 73-78.

Gaymard B., Ploner C.J., Rivaud S., Vermersch A.I., Pierro-Deseilligny C. Cortical control of saccades // Exp. Brain Res. 1998. 123. 159-163.

Hallett P.E., Adams B.D. The predictability of saccadic latency in a novel voluntary oculomotor task // Vision Res. 1980. 20. 329-339.

Jagla F., Zikmund V., Kundrat J. Differences in saccadic eye movement-related potentials under regular and irregular intervals of visual stimulation // Physiol. Res. 1994. 43. 229-232.

Jeannerod $M$. The representation brain: Neural correlates of motor intention and imagery // Behav. and Brain Sci. 1994. 17. 187-245.
Laberge D. Networks of attention // M.S. Gazzaniga (ed.). The new cognitive neurosciences. A Bradford Book. Cambridge, MA; London: The Mit Press, 2000. P. 711-724.

Posner M. Orienting of attention // J. Exp. Psychol. 1980. 32. 3-21.

Pratt $G$. Visual fixation offsets effects both the initiated and the kinematic feature of saccades // Exp. Brain Res. 1998. 118. 135-138.

Reuter-Lorens P.A., Hughes H.C., Fendrich $R$. The reduction of saccadic latency by prior fixation point offset: an analysis of the gap effect // Biol. Cybern. 1984. 50. 251-262.

Saslow M.G. Effects of components of displacement-step stimuli upon latency for saccadic eye movement // J. Opt. Soc. Am. 1967. (A). 57. 1024-1029.

Shibasaki H., Barret G., Halliday E., Halliday A. Components of the movement-related cortical potential and their scalp topography // EEG Clin. Neurophysiol. 1980. 4. 3. 213-226. 